\title{
Cancer risks in populations living near landfill sites in Great Britain
}

\author{
L Jarup*,', D Briggs', C de Hoogh', S Morris', C Hurt', A Lewin', I Maitland', S Richardson', J Wakefield' and \\ P Elliott' \\ 'The Small Area Health Statistics Unit (SAHSU), Department of Epidemiology and Public Health, Imperial College, St Mary's Campus, Norfolk Place, London \\ W2 IPG, UK
}

Previous studies have raised concerns about possible excess risks of bladder, brain and hepatobiliary cancers and leukaemias near landfill sites. Several cancers have been implicated, but no consistent pattern has emerged. We present a large nationwide analysis of selected cancers near landfill sites in Great Britain. The base population comprised people living within $2 \mathrm{~km}$ of 9565 (from a total of 19 196) landfill sites that were operational at some time from 1982 to 1997, with populations living more than $2 \mathrm{~km}$ from a landfill as reference. Risks of cancers at the above sites were computed with adjustment for age, sex, year of diagnosis, region and deprivation. National post-coded registers provided a total of 34I 856640 person-years for the adult cancer analyses and I 13631443 person-years for childhood leukaemia. There were 89786 cases of bladder cancer, 36802 cases of brain cancer, 21773 cases of hepatobiliary cancer, 37812 cases of adult leukaemia and 3973 cases of childhood leukaemia. In spite of the very large scale of this national study, we found no excess risks of cancers of the bladder and brain, hepatobiliary cancer or leukaemia, in populations living within $2 \mathrm{~km}$ of landfill sites. The results were similar if the analysis were restricted to landfill sites licensed to carry special (hazardous) waste. Our results do not support suggestions of excess risks of cancer associated with landfill sites reported in other studies.

British Journal of Cancer (2002) 86, 1732 - 1736. doi:I0.1038/sj.bjc.66003II www.bjcancer.com

(C) 2002 Cancer Research UK

Keywords: landfills; bladder cancer; brain cancer; hepatobiliary cancer; leukaemia

Several studies have suggested associations between residence near landfills containing hazardous waste and cancer. The major studies are listed in Table 1, showing that bladder cancer is the most frequently reported malignancy associated with landfills. The detoxifying properties of the liver suggest that environmental toxicants may accumulate in the liver and biliary tract; small excess risks of liver cancer were reported in previous studies around UK incinerators (Elliott et al, 1996, 2000). Several studies have shown an association between brain cancer and exposure to pesticides (Bohnen and Kurland, 1995), which are frequently used on landfill sites. Leukaemia has been associated with exposure to volatile organic compounds (VOCs), such as benzene (IARC, 1987b), which occur in emissions from landfill sites. Although several other cancers have been implicated, no consistent pattern has emerged (Vrijheid, 2000).

A wide range of waste degradation products may be released into the environment from landfill sites. Gaseous releases include primarily methane and carbon dioxide as well as smaller quantities of hydrogen sulphide, VOCs and metal vapours (Zmirou et al, 1994; Hamar et al, 1996; Ward et al, 1996). Several of these compounds (such as benzene (IARC, 1987b) and cadmium (IARC, 1993)) are classified as carcinogenic to humans (Group 1) by the International Agency for Research on Cancer (IARC). Others are considered probably (Group 2A; e.g. formaldehyde (IARC, 1995)) or possibly (Group 2B; e.g. styrene (IARC, 1994) and lead (IARC, 1987a)) carcinogenic to humans. Leaching and runoff of waste decomposition products may occur (El-Fadel et al, 1997), not only

*Correspondence: L Jarup; E-mail: I.jarup@ic.ac.uk Received 3 December 200I; revised I 8 March 2002; accepted 25 March 2002 while the site is being operated, but also after closure, as waste products continue to decay (Bozkurt et al, 2000). Human exposure to these releases potentially occurs via inhalation of polluted air, ingestion of contaminated water, or skin contact with contaminated water or soil. Monitoring of pollutants around landfill sites indicates that detectable levels of pollution tend to be confined to the immediate proximity of the site (United States Environmental Protection Agency, 1999). A recent WHO report suggested that any potential exposure is likely to be limited to $1 \mathrm{~km}$ from landfill sites by the air pathway, and $2 \mathrm{~km}$ by the water pathway (WHO, 2000). The aim of the present study was to examine the incidence of bladder, brain and hepatobiliary cancers as well as childhood and adult leukaemia near landfills in Great Britain.

\section{MATERIALS AND METHODS}

\section{Landfill sites}

Databases on landfill sites were compiled in a geographical information system (GIS), based on core data for England and Wales, provided by the Environment Agency, and for Scotland, provided by the Scottish Environment Protection Agency. In both cases, different data sets, compiled at different times, had to be merged to produce a comprehensive and consistent listing of all known landfill sites. The resulting data set comprised 19196 landfill sites (17746 in England and Wales and 1450 in Scotland) (Briggs et al, 2001).

\section{Cancer data}

We used data from England, Wales and Scotland postcoded registers, held by the UK Small Area Health Statistics Unit (SAHSU). 
Table I Studies on cancer risk associated with waste landfill sites, according to landfill site type and exposure assessment method used. Statistically significant relative risks $(R R)(P<0.05)$ reported (borderline=includes I.0)

\begin{tabular}{|c|c|c|c|}
\hline Study & Landfill site type & Exposure estimate & Cancer site showing excess risks (RR) \\
\hline Griffith et al, 1989 & Hazardous waste & Distribution of waste sites at county level & $\begin{array}{l}\text { Bladder }(2.4-5.8) \text {, stomach }(2.7-3.6) \text {, large } \\
\text { intestine }(4.3-5.9) \text {, rectum }(3.7-9.4)\end{array}$ \\
\hline Mallin, 1990 & Closed landfill site, containing hazardous waste & $\begin{array}{l}\text { Geographical study and measurements of } \\
\text { solvents in well water }\end{array}$ & Bladder $(1.7-2.6)$ \\
\hline Goldberg et al, 1995 & Domestic, commercial and industrial waste site & Distance from landfill site & $\begin{array}{l}\text { Excess risks (borderline statistical significance) } \\
\text { reported for stomach ( } 1.2-1.3) \text {, hepatoibiliary } \\
\text { (I.3), lung (I.I) and cervix cancers (I.2) }\end{array}$ \\
\hline Goldberg et al, 1999 & Municipal solid waste & $\begin{array}{l}\text { Geographic zones and distance from } \\
\text { landfill site }\end{array}$ & $\begin{array}{l}\text { Excess risks (borderline statistical significance) } \\
\text { reported for cancers of the pancreas (2.2), and } \\
\text { prostate (1.5) and non Hodgkin lymphomas (2.0) }\end{array}$ \\
\hline $\begin{array}{l}\text { Williams and } \\
\text { Jalaludin, } 1998\end{array}$ & $\begin{array}{l}\text { Domestic, commercial, industrial and } \\
\text { hazardous waste site }\end{array}$ & Distance from landfill site & Brain (3.8) \\
\hline Lewis-Michl et al, 1998 & Municipal landfill & $\begin{array}{l}\text { Buffers zones based on landfills gas } \\
\text { measurements }\end{array}$ & Bladder cancer (female, 4.1), leukaemia (female, 4.8) \\
\hline
\end{tabular}

The cancer incidence registers (Office for National Statistics (ONS) for England and Wales, Information and Statistics Division (ISD) for Scotland) included data from 1983-1997, except for Wales where data from 1983-1994 were available. For the denominators, data at enumeration district (ED) level from the 1981 and 1991 censuses were used. Populations for the years 1983 to 1990 were calculated by interpolation (Arnold, 1999, pp 10-24), and between 1992 and 1997 by distributing the ONS mid year district level estimates to EDs according to the proportions found in the 1991 census. These ED level population estimates were then used to calculate postcode level populations by point in polygon methods weighted by number of households in each postcode.

Cases were coded to the International Classification of Diseases (ICD) version 9 from 1983 to 1994 , and to version 10 thereafter. Primary outcomes were all leukaemia (ICD9204-208, ICD10 C91-C93) in children aged $0-14$ years and in adults (15+ years); bladder cancer (ICD9 188, 236.7, ICD10 C67, D41.4); brain cancer (ICD9 191-192, 225, 237.5, 237.6, 237.9, ICD10 C70-C72, D32, D33, D43), and hepatobiliary cancer (ICD9155-156, ICD10 C22-C24).

\section{Data preparation}

For the large majority of landfill sites the only locational data available were point co-ordinates (usually of the gateway). A range of locational checks was carried out on these data (e.g. by intersecting site co-ordinates with other, independent locational data, by comparison of co-ordinates given in different data files, and by intersection with district and county boundaries) and these showed that they were also subject to considerable error in some cases. This was confirmed by field visits to a selection of sites, using global positioning systems (GPS), which showed errors of 200-500 metres, although with larger errors for a small minority of sites. The data providers corrected locational errors, where possible, but despite this site co-ordinates must be seen as only a poor approximation of the location and extent of sites that may be several tens (and in some cases several hundreds) of hectares in area and may change markedly in extent over time. Similar problems also occur with the postcode data, used to define place of residence. Although these are notionally accurate to a few metres as point locations, they again represent areas of several tens of metres (in densely populated urban areas) to $>1000$ square metres (in rural areas). They are also subject to recording errors (sometimes of several hundred metres) and change over time in response to changing postal delivery patterns. In addition, landfill sites are highly clustered, so that individual postcodes may lie close to 30 or more different sites. For all these reasons, it was not considered meaningful to construct sophisticated measures of puta- tive exposure to landfill sites. As a proxy for exposure, we therefore constructed buffer zones around each of the 19196 landfill sites, using GIS techniques. In view of the limited locational accuracy of the data, a $2 \mathrm{~km}$ buffer zone was used: finer subdivision of distance from landfill sites (e.g. by constructing $1 \mathrm{~km}$ buffer zones) was not considered meaningful (Elliott et al, 2001a). The $2 \mathrm{~km}$ resolution used in this study was similar to or higher than that of previous studies (Dolk et al, 1998; Fielder et al, 2000) and at the likely limit of dispersion for landfill emissions to include both air and water pathways, and possible dispersion by birds or animals (WHO, 2000; Elliott et al, 2001a).

These $2 \mathrm{~km}$ zones were then intersected with the ca. 1.6 million postcodes in Great Britain and the exposure status of each postcode within the buffer zones classified year-on-year according to the operational status (before opening, operating, closed) and waste type (special, non-special, unknown) of the associated landfill sites, using a rule-based approach (Briggs et al, 2001). The study base comprised landfill sites that were operational at some time between 1982 and 1997; therefore postcodes for 9631 sites (49\%), which closed before 1982, opened after 1997, or for which operational data were missing or incomplete, were excluded. This left 9565 sites, comprising 774 special (hazardous) sites, 7803 non-special sites and 988 handling 'unknown' waste types. Postcodes lying outside the $2 \mathrm{~km}$ buffer zones of all landfill sites, in all years, were classified to the reference area.

Postcoded health and denominator data were matched to landfill sites by intersecting the buffer zones around the landfill sites with postcode centroids. We 'lagged' exposure by 1 year (childhood leukaemia) or 5 years (all other cancer outcomes) to allow for relevant latency periods; thus we examined data for the adult cancers from 1987-1997 and for childhood leukaemia from 1983-1997. Postcodes were assigned to tertiles of the national distribution of Carstairs' scores, an index of deprivation based on 1991 census statistics. (Carstairs and Morris, 1989), derived at the Enumeration District level.

More detailed descriptions of these methods have been published elsewhere (Briggs et al, 2001; Elliott et al, 2001a,b).

\section{Statistical analysis}

Risks for the exposed population relative to the reference population were calculated using indirect standardisation; standard stratification was felt to be too unstable because of the relatively small population falling in the reference group. Thus, we constructed a Poisson model for the observed reference data with a regression function of the covariates of interest; age, sex, year of diagnosis and standard region $(n=10)$. The most appropriate model for each cancer outcome was chosen by ascending stepwise 
selection. The selection procedure was repeated without adjustment for deprivation, and the two models constrained (where necessary) to differ only in terms of deprivation. Model predictions were then used as the reference rates in calculating expected numbers.

In order to assess the sensitivity of the results to these models, we also examined results from an alternative model that included, in addition, the most significant term excluded at the last step. Further models were run including a measure of urban/rural status.

We calculated $99 \%$ confidence intervals around the relative risk estimates using a Poisson model for rare events, assuming a common relative risk for all landfill sites. To the extent that the model assumptions fail to hold (for example, because of data anomalies, unmeasured confounding or sampling variability in the rates) some degree of over-dispersion and a widening of the confidence intervals is to be expected.

\section{RESULTS}

Overall, 341856640 person-years for the adult cancers and 113631443 person-years for childhood leukaemia were included in the study. Within $2 \mathrm{~km}$ of landfills, 31,34 and $35 \%$ of the population were in Carstairs' tertiles 1 (most affluent), 2 and 3 (most deprived) respectively compared with 44,32 and $23 \%$ respectively in the reference area. Thus, the populations living near landfills were more deprived than populations in the reference area.

Table 2 shows the risks of bladder cancer, brain cancer, hepatobiliary cancer and leukaemia within $2 \mathrm{~km}$ of all sites open at any time during the study period. A $4 \%$ excess of bladder cancer in the models with deprivation excluded reduced to $1 \%$ (99\% confidence limits: $0-2 \%$ ) once deprivation was added. With full adjustment, no excess risk of any other cancer was found, nor was there excess risk of any cancers near the sub-set of landfill sites licensed to carry special (hazardous) waste (Table 3 ). The results were robust to the models used in the sensitivity analysis. Detailed results are available in a downloadable report at the Department of Health web-site (Elliott et al, 2001b).

\section{DISCUSSION}

This is by far the largest study to report on the possible association between residence near landfill and cancer risk. We did not find any excess risks for the cancers studied, in contrast to previous studies where excess risks of bladder cancer (Griffith et al, 1989; Lewis-Michl et al, 1998; Mallin, 1990), brain cancer (Williams and Jalaludin, 1998), hepatobiliary cancer (Goldberg et al, 1995) and leukaemia (Lewis-Michl et al, 1998) have been reported.

Table 2 Risks of bladder cancer, brain cancer, hepatobiliary cancer and leukaemia, in populations living within 2 km of a landfill site open at any time during the study period. Unadjusted rates and rate ratios as well as rate ratios adjusted for age, sex, year of diagnosis (not for leukaemia) and region, without and with adjustment for deprivation. A 5-year latency period was applied for the solid tumours and adult leukaemia, I year for childhood leukaemia

\begin{tabular}{|c|c|c|c|c|c|c|c|}
\hline Outcome & \multicolumn{2}{|c|}{$<2 \mathbf{k m}^{\mathrm{a}}$} & \multicolumn{2}{|c|}{$\geqslant 2 \mathbf{k m}^{\mathbf{b}}$} & \multicolumn{3}{|c|}{ Rate ratio } \\
\hline Bladder cancer & 63367 & 2640 & 26419 & 2594 & 1.02 & $\begin{array}{c}1.04 \\
(1.03-1.05)\end{array}$ & $\begin{array}{c}1.01 \\
(1.00-1.02)\end{array}$ \\
\hline Brain cancer & 25452 & 1060 & 11350 & 1114 & 0.95 & $\begin{array}{c}0.98 \\
(0.96-0.99)\end{array}$ & $\begin{array}{c}0.99 \\
(0.98-1.01)\end{array}$ \\
\hline Adult leukaemia & 26279 & 1095 & 11533 & 1132 & 0.97 & $\begin{array}{c}0.99 \\
(0.97-1.00)\end{array}$ & $\begin{array}{c}0.99 \\
(0.98-1.01)\end{array}$ \\
\hline Childhood leukaemia & 2886 & $350^{d}$ & 1087 & $350^{e}$ & 1.00 & $\begin{array}{c}0.93 \\
(0.89-0.98)\end{array}$ & $\begin{array}{c}0.96 \\
(0.91-1.00)\end{array}$ \\
\hline
\end{tabular}

${ }_{2}^{a} 40015710$ person-years. ${ }^{b} 101840930$ person-years. ${ }^{c}$ per 10000000 person-years. d82 543477 person-years. e31 087966 person-years.

Table 3 Risks of bladder cancer, brain cancer, hepatobiliary cancer and leukaemia, in populations living within $2 \mathrm{~km}$ of a special waste landfill site open at any time during the study period. Unadjusted rates and rate ratios as well as rate ratios adjusted for age, sex, year of diagnosis (not for leukaemia) and region, without and with adjustment for deprivation. A 5-year latency period was applied for the solid tumours and adult leukaemia, I year for childhood leukaemia

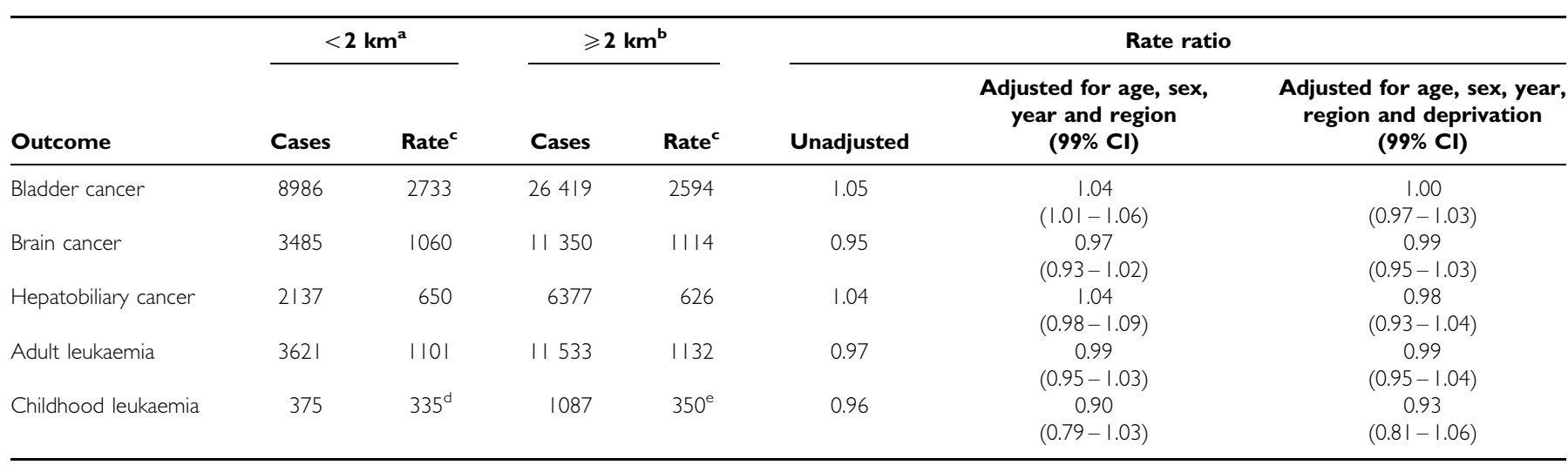

${ }^{a} 32877335$ person-years. ${ }^{b} 101840930$ person-years. ${ }^{c}$ per 10000000 person-years. ${ }^{d}$ II 209350 person-years. ${ }^{e} 31087966$ person-years. 
In interpreting our results, the possibility of a false negative finding needs to be considered. Various sources of error and uncertainty are present in the data. The landfills data, for example, are subject to errors in location, operating dates and classification of waste types. Although every effort was made to obtain as complete as possible a national inventory of waste sites, nonetheless some landfill sites may be missing from the database (especially older sites which closed before licensing was enforced). Use of a point location (the gateway or centroid of the boundary polygon) to define sites contributes to these uncertainties: landfill sites vary greatly in terms of their surface area, from $50 \mathrm{~m}^{2}$ to 70 million $\mathrm{m}^{2}$ (average $64600 \mathrm{~m}^{2}$ ), and the areas and locations change over time as sites evolve. Postcode locations (used to locate the cancer cases with respect to landfill sites) are only accurate to around 100 metres on average.

These uncertainties precluded the use of more sophisticated measures to define exposure near a landfill, and no direct measures were available. There is in any case considerable uncertainty as to the extent of any possible exposure to chemicals found in landfill sites (Pershagen, 1998). Such field monitoring as has been undertaken suggests that pollutants released from landfill sites are detectable only within very small distances of the sites (United States Environmental Protection Agency, 1999). It is therefore possible that any very local effects near landfill sites within our study, or perhaps effects restricted to a small sub-set of landfill sites only, may not have been detected. Possible effects of multiple, or differential, exposures from different landfill sites were also not considered. In addition, latency times, in particular for the solid tumours, and migration in and out of the study areas, may give rise to substantial misclassification with respect to potential exposure to landfill, leading to dilution of any potential effect. However, given that $80 \%$ of the population lives within $2 \mathrm{~km}$ of a landfill site and is therefore considered as 'exposed' in this study, it is likely that a person who moves out of an 'exposed' area will move into another 'exposed' area. Thus, the potential bias of migration may

\section{REFERENCES}

Arnold R (1999) SAHSU methods for estimating population in small areas. In Population Counts in Small Area Studies: Implications for Studies of Environment and Health, Arnold R, Elliott P, Wakefield J, Quinn M (eds) pp 10-24 London, UK: HMSO

Bohnen NI, Kurland LT (1995) Brain tumor and exposure to pesticides in humans: a review of the epidemiologic data. J Neurol Sci 132: 110-121

Bozkurt S, Moreno L, Neretnieks I (2000) Long-term processes in waste deposits. Sci Total Environ 250: $101-121$

Briggs D, de Hoogh C, Hurt C, Maitland I (2001) A geographical analysis of populations living around landfill sites. London: Small Area Health Statistics Unit, Imperial College. SAHSU Technical Report; 1

Carstairs V, Morris R (1989) Deprivation: explaining differences between mortality between Scotland and England. BMJ 299: 886-889

Dolk H, Vrijheid M, Armstrong B, Abramsky L, Bianchi F, Garne E, Nelen V, Robert E, Scott JES, Stone D, Tenconi R (1998) Risk of congenital anomalies near hazardous-waste landfill sites in Europe: the EUROHAZCON study. Lancet 352: $423-427$

El-Fadel M, Findikakis AN, Leckie JO (1997) Environmental impacts of solid waste landfilling. J Environ Manage 50: 1-25

Elliott P, Shaddick G, Kleinschmidt I, Jolley D, Walls P, Beresford J, Grundy $\mathrm{C}$ (1996) Cancer incidence near municipal solid waste incinerators in Great Britain. Br J Cancer 73: $702-710$

Elliott P, Eaton N, Shaddick G, Carter R (2000) Cancer incidence near municipal solid waste incinerators in Great Britain. Part 2: histopathological and case-note review of primary liver cancer cases. Br J Cancer 82: 1103-1106

Elliott P, Briggs D, Morris S, de Hoogh C, Hurt C, Kold Jensen T, Maitland I, Richardson S, Wakefield J, Jarup L (2001a) Risk of adverse birth outcomes in populations living near landfill sites. BMJ 323: $363-368$ be less pronounced in this study than in other epidemiological studies where potential exposure commonly is confined to a small part of the population.

In an ecological study such as that considered here, the sources of bias are more complicated than in an individual-level study, and hence the interpretation of estimated rates is more complex (Greenland and Robins, 1994). In particular, the within-area variability in exposure and potential confounders leads to a greater possibility of confounding, and in the absence of within-area data, it may not be possible to control adequately for such confounding. In this particular example, no effect of residence near landfill sites on cancer risk was found, although it is of course possible that unmeasured confounding working in the opposite direction could have masked a true effect.

In conclusion, we found no excess risks of bladder, brain or hepatobiliary cancer, or leukaemia, in populations living close to landfill sites. Our results do not support suggestions of excess risks of cancer associated with landfill sites reported in other studies.

\section{ACKNOWLEDGEMENTS}

The Small Area Health Statistics Unit is funded by a grant from the Department of Health, Department of the Environment, Food and Rural Affairs, Environment Agency, Health and Safety Executive, Scottish Executive, National Assembly for Wales and Northern Ireland Assembly. We thank the Office for National Statistics (ONS) and the Information and Statistics Division of the Scottish Health Service for provision of cancer data; and the Environment Agency in England and Wales, and the Scottish Environment Protection Agency for provision of data on landfill, and for their help in resolving discrepancies. The views expressed in this publication are those of the authors and not necessarily those of the funding departments, data providers or of ONS.
Elliott P, Morris S, Briggs D, de Hoogh C, Hurt C, Kold Jensen T, Maitland I, Lewin A, Richardson R, Wakefield J, Jarup L (2001b) Birth outcomes and selected cancers in populations living near landfill sites. Report to the Department of Health August 2001b. (http://www.doh.gov.uk/ oldnews.htm)

Fielder HM, Poon-King CM, Palmer SR, Moss N, Coleman G (2000) Assessment of impact on health of residents living near the Nant-y-Gwyddon landfill site: retrospective analysis. BMJ 320: $19-22$

Goldberg MS, al-Homsi N, Goulet L, Riberdy H (1995) Incidence of cancer among persons living near a municipal solid waste landfill site in Montreal, Quebec. Arch Environ Health 50: 416-424

Goldberg MS, Siemiatycki J, DeWar R, Desy M, Riberdy H (1999) Risks of developing cancer relative to living near a municipal solid waste landfill site in Montreal, Quebec, Canada. Arch Environ Health 54: $291-296$

Greenland S, Robins J (1994) Invited commentary: ecologic studies-biases, misconceptions, and counterexamples. Am J Epidemiol 139: $747-760$

Griffith J, Duncan RC, Riggan WB, Pellom AC (1989) Cancer mortality in U.S. counties with hazardous waste sites and ground water pollution. Arch Environ Health 44: 69-74

Hamar GB, McGeehin MA, Phifer BL, Ashley DL (1996) Volatile organic compound testing of a population living near a hazardous waste site. $J$ Expo Anal Environ Epidemiol 6: $247-255$

IARC (1987a) Monographs on the Evaluation of Carcinogenic Risks to Humans Some Metals and Metallic Compounds. Intl Agency Res Cancer, Lyon 23(Suppl. 7): 325-438

IARC (1987b) Monographs on the Evaluation of Carcinogenic Risks to Humans. Some Industrial Chemicals and Dyestuffs. Intl Agency Res Cancer, Lyon 29(Suppl. 7): $93-148$ 
IARC (1993) Monographs on the Evaluation of Carcinogenic Risks to Humans. Beryllium, Cadmium, Mercury, and Exposures in the Glass Manufacturing Industry. Intl Agency Res Cancer, Lyon 58: 119-238

IARC (1994) Monographs on the Evaluation of Carcinogenic Risks to Humans Some Industrial Chemicals. Intl Agency Res Cancer, Lyon 60: $233-320$

IARC (1995) Monographs on the Evaluation of Carcinogenic Risks to Humans. Wood Dust and Formaldehyde. Intl Agency Res Cancer, Lyon 62: $217-405$

Lewis-Michl EL, Kallenbach LR, Geary NS, Melius JM, Ju CL, Orr MF, Forand SP (1998) Investigation of cancer incidence and residence near 38 landfills with soil gas migration conditions, New York State, 1980 1989. Report for Grant \#H75/ATH298290-01 to the Department of Health and Human Sciences, Agency for Toxic Substances and Disease Registry, Atlanta, Georgia

Mallin K (1990) Investigation of a bladder cancer cluster in northwestern Illinois. Am J Epidemiol 132(Suppl): S96-S106

Pershagen G (1998) Environmental epidemiology in public health. Lancet 352: 417
United States Environmental Protection Agency (1999) Revised Risk Assessment for the Air Characteristic Study. Overview 530-R-99-19a. US EPA, Office of Solid waste

Vrijheid M (2000) Health effects of residence near hazardous waste landfill sites: a review of epidemiologic literature. Environ Health Perspect 108(Suppl 1): $101-112$

Ward RS, Williams GM, Hills CC (1996) Changes in major and trace components of landfill gas during subsurface migration. Waste Manage Res 14: $243-261$

WHO (2000) Methods of assessing risk to health from exposure to hazards released from waste landfills. Report from a WHO Meeting Lodz, Poland, 10 - 12 April, 2000. Bilthoven, The Netherlands: WHO Regional Office For Europe, European Centre for Environment and Health

Williams A, Jalaludin B (1998) Cancer incidence and mortality around a hazardous waste depot. Aust N Z J Public Health 22: 342-346

Zmirou D, Deloraine A, Saviuc P, Tillier C, Boucharlat A, Maury N (1994) Short-term health effects of an industrial toxic waste landfill: a retrospective follow-up study in Montchanin, France. Arch Environ Health 49: 228 238 